\title{
RESPIRATORY FUNCTIONS IN TEXTILE MILL WORKERS: ROLE OF PEAK EXPIRATORY FLOW RATE
}

\section{SEEMA GUPTA ${ }^{1 *}$, VARUN MALHOTRA ${ }^{1}$, YOGESH TRIPATHI $^{1}$, PRATIBHA DEV $^{2}$}

${ }^{1}$ Department of Physiology, Santosh Medical College and Hospital, Santosh University, Ghaziabad, Uttar Pradesh, India. ${ }^{2}$ Department of Physiology, Venkateshwara Institute of Medical Sciences, Gajraula, Uttar Pradesh, India. Email: drguptaseema1967@gmail.com

Received: 23 December 2016, Revised and Accepted: 04 January 2017

\section{ABSTRACT}

Background: Textile industries play a significant role in the economic growth of the country. Health concern of these textile mill workers is the biggest challenge. Respiratory alterations were found in these workers with long-term exposure to cotton dust. Effect of cotton dust on peak expiratory flow rate (PEFR) is not very well documented in the past.

Aim/Objective: The main objective of this study was the assessment of respiratory functions in textile mill workers along with the effect on PEFR in these workers.

Methods: A total of 130 male textile mill workers were recruited for this study from the different sections of a textile mill. In which, 80 workers were present from exposed and remaining 50 were from non-exposed area of a textile mill. 30-40 years of age workers with the working history of not more than 5 years, were included in the part of the study. Their body mass index (BMI) and respiratory functions were evaluated. BMI was calculated using weight and height of an individual. Respiratory functions including forced vital capacity (FVC) and forced expiratory volume in 1 second (FEV ) $_{1}$ were estimated using spirometer, and PEFR was measured by Wright's peak flow meter.

Results: The mean values of FVC, $\mathrm{FEV}_{1}$, and PEFR were found to be significantly $(<0.01)$ lower in the exposed group of the textile mill when compared non-exposed groups. When these values were compared on the basis of BMI, workers with BMI $>25 \mathrm{~kg} / \mathrm{m}^{2}$ were found with lower mean values of FVC, $\mathrm{FEV}_{1}$, and PEFR when compared with workers with $\mathrm{BMI}<25 \mathrm{~kg} / \mathrm{m}^{2}$. Furthermore, there was significant $(<0.05)$ negative correlation between BMI and PEFR in both exposed group and non-exposed group of a textile mill.

Conclusion: Workers at the textile mill, with short-term exposure to cotton dust, may also present with respiratory alterations which may increase with long-term exposure. Safety controls, such as ventilation, and routine health check are very much required in textile industries.

Keywords: Peak expiratory flow rate, Body mass index, Textile mill.

(C) 2017 The Authors. Published by Innovare Academic Sciences Pvt Ltd. This is an open access article under the CC BY license (http://creativecommons. org/licenses/by/4. 0/) DOI: http://dx.doi.org/10.22159/ajpcr.2017.v10i4.16757

\section{INTRODUCTION}

Occupational health is one of the biggest challenges in the present scenario. Different kind of industries is growing day by day in developed as well as developing countries [1]. Textile industries are one of the most common occupations since more than 20 million workers are involved in textile manufacturing in India [2]. Continuous exposure in that situation or working environment may affect the health of their workers [3]. The variety of factors may affect the functioning of these workers due to exposure to cotton fibers in the textile industry [4]. Respiratory or pulmonary functions seem to be the most affected system in the body due to exposure to cotton fibers since the female workers based study from Maharashtra reported that subclinical expiratory function impairment may present in these workers [5]. However, a loom workers based study did not reveal any respiratory dysfunctioning in their workers [6]. Peak expiratory flow rate (PEFR), an effort dependent test, reflects the status of large airways [7]. It is the best measurement of fast exhalation of an individual and commonly used for testing breath shortness, cough, and wheezing [8]. Measurement of PEFR along with other parameters of respiratory function may provide the better understanding of pulmonary symptoms in textile workers. Hence, the main objective of this study was the assessment of pulmonary functions in exposed as well as non-exposed workers of a textile mill.

\section{MATERIALS AND METHODS}

This cross-sectional study was conducted in the Department of Physiology, Santosh Medical College and Hospital, Ghaziabad. There were 130 male workers recruited from various sections of a textile mill in which 80 workers were exposed to cotton dust and remaining 50 workers were non-exposed to cotton dust. The age group criteria for this study population were 30-40 years. All the participants were voluntarily participated to be the part of the study. The written and oral consent was obtained from all the participants before the beginning of the study. This study was ethically approved by the Institutional Ethical Committee of Santosh Medical College and Hospital, Ghaziabad.

\section{Exclusion criteria}

- Workers suffering from known respiratory disorder, i.e., chest infection, cold, cough, tuberculosis, chronic obstructive pulmonary disorder, and chest tightness [9].

- Workers on medication for pulmonary ailments - i.e., asthafen and asthalin - were also excluded from the study.

- Workers having the working history in textile mill $>5$ years were also excluded.

- Workers working $>8 \mathrm{hrs}$ were not including in the study.

- Smokers, alcoholics or tobacco users were also excluded. 


\section{Inclusion criteria}

- Only 130 textile mill workers, 35-55 years of age group without having the previous history of respiratory disorder were included in the study.

\section{Methods}

1. Standing height: Height of the study group's individuals was recorded without shoes by using stadiometer.

2. Weight: Weight of every person from the study group was measured without shoes and light clothes, by using the digital weight machine.

3. Body mass index (BMI): BMI of an individual is expressed in $\mathrm{kg} / \mathrm{m}^{2}$ and can be defined by the weight of that person, which is divided by the square of the height of that person. The weight and height were expressed in kilogram and meter, respectively [10].

4. Lung functions test [11]:

a. Forced vital capacity (FVC): FVC was measured by Spirometry method

b. Forced expiratory volume in 1 second $\left(\mathrm{FEV}_{1}\right)$ : $\mathrm{FEV}_{1}$ was also measured by Spirometry method.

c. PEFR defined as person's expiratory flow rate, was measured by Wright's mini peak flow meter [12].

\section{Statistical analysis}

All the parameters (age, height, weight, BMI, FVC, FEV ${ }_{1}$, and PEFR) were expressed in mean \pm standard deviation. An unpaired Student's t-test was used to differentiate various parameters between the groups. A Pearson correlation coefficient was used for the association of BMI with PEFR. A $p<0.05$ was considered statistically significant. A statistical software IBM-Statistical Package for Social Sciences version 23.0 was used for statistical analysis.

\section{RESULTS}

There nonsignificant and significant results were obtained between the exposed and non-exposed groups of this study population. Height and weight of this study population were not significantly different between the groups. BMI was different between the groups but their findings were nonsignificant $(>0.05)$. While in the case of respiratory functions, the significant results were obtained between exposed and non-exposed group. FVC and $\mathrm{FEV}_{1}$ were lower in exposed group when compared with non-exposed group of a textile mill. These findings were significant $(<0.05)$. Similarly, PEFR was also found to be significantly $(<0.05)$ lower in exposed group of a Textile mill in compared to nonexposed group (Table 1). While comparing this whole study population on the basis of BMI, FVC, FEV and PEFR was found to be lower in the population having BMI $>25 \mathrm{~kg} / \mathrm{m}^{2}$ when compared with workers having $\mathrm{BMI}<25 \mathrm{~kg} / \mathrm{m}^{2}$. This result was significant in FVC and PEFR but not in $\mathrm{FEV}_{1}(>0.05)$ (Table 2). And further comparing the exposed group on basis of BMI and PEFR was found to be significantly lower in workers having $\mathrm{BMI}>25 \mathrm{~kg} / \mathrm{m}^{2}$ (Fig. 1). There was a negative association between PEFR and BMI in both exposed and non-exposed group of this study population. This association was highly significant in both the groups (Table 3).

\section{DISCUSSION}

Occupational health is one of the biggest challenges of present time. Various environmental factors, working conditions, and occupational status from different sectors put a great impact on a health of an individual [13]. Long-term exposure to cotton dust was found to associated obstructive disease which increases with the duration of exposure and correlated with the pulmonary function [14]. The altered findings of our study also support this since the workers in this study were not suffering from any disease. Altered respiratory functions in the exposed group of textile mill workers were found in this study when compared to non-exposed group. This finding was supported by Ramaswamy et al. study when they reported poor pulmonary functions in textile mill workers [15]. There was decreased level of FVC was observed in exposed group when compared to non-exposed group. A study from Sangeeta vyas also supported this result when
Table 1: Baseline parameters between textile and nontextile workers $^{\#}$

\begin{tabular}{lllll}
\hline S. No. & Variables & $\begin{array}{l}\text { Exposed } \\
\text { group }\end{array}$ & $\begin{array}{l}\text { Non-exposed } \\
\text { group }\end{array}$ & p value \\
\hline 1. & Age & $44.61 \pm 8.71$ & $44.92 \pm 7.59$ & 0.832 \\
2. & Height & $167.56 \pm 5.53$ & $166.88 \pm 4.75$ & 0.457 \\
3. & Weight & $70.91 \pm 10.47$ & $68.36 \pm 8.78$ & 0.137 \\
4. & BMI & $25.22 \pm 3.41$ & $24.51 \pm 2.81$ & 0.201 \\
5. & FVC & $144.75 \pm 35.81$ & $178.34 \pm 42.49$ & $<0.001$ \\
6. & FEV & $143.91 \pm 36.38$ & $192.24 \pm 36.46$ & $<0.001$ \\
7. & PEFR & $114.54 \pm 24.19$ & $166.28 \pm 12.76$ & $<0.001$ \\
\hline
\end{tabular}

All the variables were expressed in mean \pm SD. $p<0.05$ is statistically significant, \#By using unpaired Student's t-test. BMI: Body mass index, FVC: Forced vital capacity, $\mathrm{FEV}_{1}$ : Forced expiratory volume in 1 second, PEFR: Peak expiratory flow rate, SD: Standard deviation

Table 2: Respiratory functions on the basis of BMI among study population"

\begin{tabular}{lllll}
\hline S. No. & Parameters & $\mathbf{B M I}<\mathbf{2 5} \mathbf{~ k g} / \mathbf{m}^{\mathbf{2}}$ & $\mathbf{B M I}>\mathbf{2 5} \mathbf{k g} / \mathbf{m}^{\mathbf{2}}$ & $\mathbf{p}$ value \\
\hline 1. & FVC & $164.45 \pm 39.59$ & $147.82 \pm 43.12$ & 0.028 \\
2. & FEV $_{1}$ & $167.36 \pm 40.08$ & $155.43 \pm 47.03$ & 0.135 \\
3. & PEFR & $141.92 \pm 26.77$ & $123.56 \pm 37.08$ & 0.003 \\
\hline
\end{tabular}

All the variables were expressed in mean \pm SD. $p<0.05$ is statistically significant "By using unpaired student's t-test. BMI: Body mass index, FVC: Forced vital

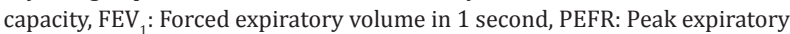
flow rate, SD: Standard deviation

Table 3: Pearson correlation between BMI and PEFR in study population*

\begin{tabular}{llll}
\hline S. No. & Groups & r value & p value \\
\hline 1. & Exposed group & -0.60 & $<0.001$ \\
2. & Non-exposed group & -0.36 & 0.010 \\
\hline
\end{tabular}

$\mathrm{p}<0.05$ is statistically significant, ${ }^{*}$ By using Pearson correlation coefficient. BMI: Body mass index, PEFR: Peak expiratory flow rate

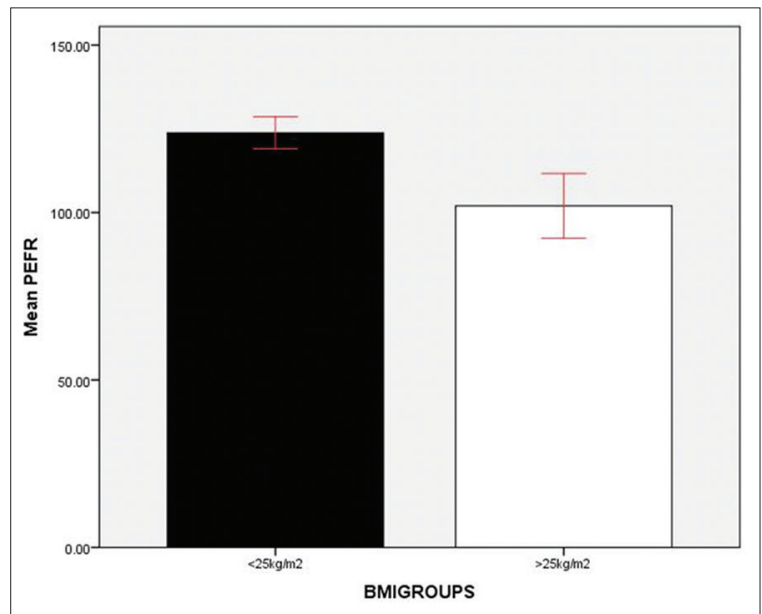

Fig. 1: Presentation of peak expiratory flow rate in exposed group of textile mill

they observed the decreased level of FVC and $\mathrm{FEV}_{1}$ [16]. The mean level of $\mathrm{FEV}_{1}$ was also found to be increased in non-exposed group when compared to exposed group. In support to this, a study based on nonsmokers textile workers also observed similar findings when they observed a positive association between duration of exposure to cotton dust to reducing lung functioning after getting increased FVC and FEV in control group when compared to cotton mill workers [17]. 
PEFR, the simplest estimate for lung functions [18], indicates the severity of airflow limitation [19]. Rao et al. observed an inverse relationship between chronic exposure to cotton dust and pulmonary functions after observing decreased level of PEFR in cotton mill workers [20]. There was decreased level of PEFR was observed in the exposed group of textile mill workers compared to non-exposed workers. Moreover, a Nigerian based study also reported a significant decrease in FVC, $\mathrm{FEV}_{1}$, and PEFR in exposed workers from a textile mill when compared to unexposed group similar to this study [21]. An increased BMI also plays a significant role in increasing health-related issues. Obese people generally presented with higher respiratory rated and lower tidal volumes [22] similar to this study since after comparing this study population on the basis of BMI there was the decreased level of FVC, FEV and PEFR were observed in those having increased BMI $\left(>25 \mathrm{kgm}^{2}\right)$. PEFR generally depends on the various factors, i.e., age, sex, and height [23]. A negative correlation between BMI and PEFR in both exposed and non-exposed textile workers in this study was supported by Gupta et al. study [24]. This negative association also supported by Shobana et al. when they observed a negative association between PEFR and BMI in both power loom workers and nonpower loom workers [25]. This study shows a significant reduction in respiratory functions due to continuous exposure to cotton dust supported by Dube et al. study [26].

\section{CONCLUSION}

The outcome of this research shows the reduced pulmonary function in the exposed group of the textile mill which may lead to severe disorder in later stage due to continuous exposure of cotton fibers. As far as this research is concerned, there was no previous history of respiratory disorders in textile workers; therefore, the findings of this study are not due to the consequence of any known disorder. The only limitation of this was to its sample size, more studies should be conducted on with more sample size on large scale. Hence, our recommendation is, workers should be notified about the working conditions and their health status should be routinely checked up. Safety protocol - e.g., good housekeeping, self-protection, cleaning of equipment and ventilation - should be properly followed while working in textile mills.

\section{REFERENCES}

1. Meswani HR. Safety and occupational health: Challenges and opportunities in emerging economies. Indian J Occup Environ Med 2008;12(1):3-9.

2. Mishra AK, Rotti SB, Sahai A, Madanmohan, Narayan KA. Byssinosis among male textile workers in Pondicherry: A case-control study. Natl Med J India 2003;16(2):70-3

3. Froneberg B. Challenges in occupational safety and health from the global market economy and from demographic change-facts, trends, policy response and actual need for preventive occupational health services in Europe. SJWEH Suppl 2005;1:23-7.

4. Rao NM, Kulkarni PK. Pulmonary function evaluation in subjects occupationally exposed to toxic dust and pollutants. Indian J Ind Med 1995;41:162-6.
5. Jadhav AJ, Mankar SR, Dange CD. Effect of exposure of cotton dust on pulmonary function tests in female workers of spinning mill at Malegaon, Maharashtra. Int J Med Res Rev 2016;4:1233-8.

6. Nisar A, Neyaz HS, Deepankar AS. A study of peak expiratory flow rate in loom workers. JARBS 2013;5(3):247-9.

7. Saji MO, Alhas JJ, Siraj S. Study on the impact of patient counseling on the quality of life and pulmonary function of asthmatic patient. Int $\mathrm{J}$ Pharm Pharm Sci 2012;4 Suppl 5:300-4.

8. Venkatesan EA, Walter S, Ray D. An evaluation of the assess peak flow meter on human volunteers. Indian J Physiol Pharmacol 1994;38(4):285-8

9. Reema T, Adepu R, Sabin T. Impact of clinical pharmacist intervention on knowledge, attitude and practice (KAP) of patients with chronic obstructive pulmonary disease. Int J Pharm Pharm Sci 2010;2(4):54-7.

10. Garrow JS, Webster J. Quetelet's index (W/H2) as a measure of fatness. Int J Obes 1985;9(2):147-53.

11. Meenakshi S, Gajalakshmi BS. An easy method of spirometry. J Assoc Physicians India 1993;41(5):284-6.

12. Wright BM. A miniature Wright peak-flow meter. $\mathrm{Br}$ Med J 1978;2(6152):1627-8.

13. Lucchini RG, London L. Global occupational health: Current challenges and the need for urgent action. Ann Glob Health 2014;80(4):251-6.

14. Mansouri F, Pili JP, Abbasi A, Soltani M, Izadi N. Respiratory problems among cotton textile workers. Lung India 2016;33(2):163-6.

15. Ramaswamy P, Sambandam S, Ramalingam A, Arnold J, Balakrishnan KF, Thanasekaraan V. Pulmonary functions of workers in textile units of Tamil Nadu, India: Isee-386. Epidemiology 2003;14(5):S76.

16. Vyas S. A study of pulmonary function tests in workers of different dust industries. Int J Basic Appli Med Sci 2012;2(2):15-21.

17. Rao DP, Aruna T. Lung function among non-smoking cotton mill workers. Indian J Appl Res 2016;6(5):23-4.

18. Al-Taweel AA, Kalantan KA, Ghani HA. Peak expiratory flow rate in a sample of normal Saudi males at Riyadh, Saudi Arabia. J Family Community Med 1999;6(1):23-7.

19. Charlton I, Charlton G, Broomfield J, Mullee MA. Evaluation of peak flow and symptoms only self management plans for control of asthma in general practice. BMJ 1990;301(6765):1355-9.

20. Rao KP, Srinivasarao CH, Sumangali P. A study of pulmonary function tests in cotton mill workers of Guntur district. Bull Pharm Med Sci 2013;1:206-9.

21. Nagoda M, Okpapi JU, Babashani M. Assessment of respiratory symptoms and lung function among textile workers at Kano textile mills, Kano, Nigeria. Niger J Clin Pract 2012;15:373-9.

22. Littleton SW. Impact of obesity on respiratory function. Respirology 2012;17:43-9.

23. Guidelines for Management of Asthma in Adults: I - Chronic Persistent Asthma. Statement by the British thoracic society, research unit of the royal college of physicians of London, King's fund centre, national asthma campaign. BMJ 1990;301(6753):651-3.

24. Gupta S, Gupta R, Gupta G, Gupta C. To study the effect of pulmonary functions in overweight persons in rural area population. Int J Contemp Med 2015;3(2):105-9.

25. Shobana BV, Krishnan GV, Milind V, Bhutkar V. Comparative study of body mass index with pulmonary function test parameter (Peak expiratory flow rate) among power loom and non powerloom workers in rural area in Salem district. Br J Med Health Res 2015;2(6):9-14

26. Dube KJ, Ingale LT, Ingle ST. Respiratory impairment in cottonginning workers exposed to cotton dust. Int J Occup Saf Ergon 2013;19(4):551-60. 